\title{
BMJ
}

\section{Genus $\beta$ human papillomaviruses and incidence of basal cell and squamous cell carcinomas of skin: population based case-control study}

\author{
Margaret R Karagas, professor, ${ }^{1}$ Tim Waterboer, post doctoral fellow, ${ }^{2}$ Zhongze Li, statistical analyst, \\ Heather $\mathrm{H}$ Nelson, associate professor, ${ }^{3}$ Kristina M Michael, post doctoral fellow, ${ }^{2}$ Jan Nico Bouwes Bavinck, \\ professor, ${ }^{4}$ Ann E Perry, associate professor, ${ }^{1}$ Steven K Spencer, professor, ${ }^{1}$ Janet Daling, professor emeritus, ${ }^{5}$ \\ Adele C Green, professor, ${ }^{6}$ Michael Pawlita, scientist ${ }^{2}$ for the New Hampshire Skin Cancer Study Group
}

Section of Biostatistics and Epidemiology, Department of Community and Family Medicine and Norris Cotton Cancer Center. Dartmouth Medical School, Lebanon, NH, 03756, USA

${ }^{2}$ German Cancer Research Center (DKFZ), 69120 Heidelberg, Germany

${ }^{3}$ Masonic Cancer Center, University of Minnesota, Minneapolis, MN, 55455, USA

${ }^{4}$ Leiden University Medical Center 2300 RC Leiden, Netherlands

${ }^{5}$ University of Washington and Fred Hutchinson Cancer Research Center, Seattle, WA, 98109, USA

${ }^{6}$ Queensland Institute of Medical Research, PO Royal Brisbane Hospital, Qld 4029, Australia

Correspondence to: M Karagas margaret.karagas@dartmouth.edu

Cite this as: BMJ 2010;341:c2986 doi:10.1136/bmj.c2986

\section{ABSTRACT}

Objective To investigate the association between genus $\beta$ human papillomaviruses and the incidence of nonmelanocytic skin cancer in the general population. Design Population based case-control study.

Setting New Hampshire, USA.

Participants 2366 skin cancer cases and controls from the general population aged 25 to 74 years ( 663 squamous cell carcinoma, 898 basal cell carcinoma, 805 controls), with plasma samples tested for L1 antibodies to 16 genus $\beta$ human papillomaviruses by multiplex serology.

Main outcome measures Odds ratios for squamous cell carcinoma and basal cell carcinoma associated with seropositivity to $\beta$ human papillomaviruses.

Results Squamous cell carcinoma, but not basal cell carcinoma, cases had a higher prevalence of each of the individual $\beta$ human papillomaviruses assayed compared with controls. The odds ratios for squamous cell carcinoma increased with the number of $\beta$ types positive (odds ratio for one type positive 0.99 ( $95 \%$ confidence interval 0.74 to 1.33 ); two to three types positive 1.44 (1.03 to 2.01); four to eight types positive 1.51 (1.03 to 2.20); more than eight types positive 1.71 (1.12 to 2.62); $\mathrm{P}$ for trend (categorical)<0.001; P for trend (continuous) $=0.003$ ). With limited statistical power, the association was stronger among long term users of systemic glucocorticoids (odds ratio $3.21,1.22$ to 8.44 ) than among non-users (1.23, 0.97 to 1.55).

Conclusions These findings support a relation between genus $\beta$ human papillomavirus infection and the incidence of squamous cell carcinoma of the skin in the general population, as well as potential enhancement of risk by immunosuppression.

\section{INTRODUCTION}

In many regions of the world, cancers arising from keratinocytes or their precursors (such as basal cell carcinoma and squamous cell carcinoma) comprise the most common malignancies, and the incidence rates may be increasing rapidly. ${ }^{1}$ As these often occur near vital structures (such as the eye, nose, and ears), they can cause considerable disfigurement and even death in certain subgroups of the population, such as immunosuppressed people. ${ }^{1}$ Although ultraviolet radiation is the main established risk factor, exposure to this has not been easy to target for prevention or treatment.

Human papillomavirus infection is hypothesised to play a role in the pathogenesis of non-melanocytic skin cancer; if this is true, it would have important clinical and public health implications. Papillomaviruses are epitheliotropic, non-enveloped, double stranded DNA viruses, of which more than 100 different types have been identified. ${ }^{2}$ Genus $\beta$ papillomaviruses, notably human papillomaviruses 5 and 8 , were first identified in non-melanocytic skin cancers of patients with epidermodysplasia verruciformis, a rare genetic disorder characterised by defective cell mediated immunity, manifesting diffuse warty and malignant skin lesions. The International Agency for Research on Cancer's 2007 monograph on human papillomaviruses recognised human papillomaviruses 5 and 8 as being "carcinogenic to patients with epidermodysplasia verruciformis" but with limited evidence for carcinogenicity in the general population. ${ }^{3} \mathrm{~A}$ higher prevalence of antibodies to $\beta$ human papillomavirus has been detected among cases of squamous cell carcinoma than controls in largely clinic based studies with inadequate statistical power. Few population based studies of these malignancies exist, partly because they are typically excluded from cancer registries. ${ }^{4-11}$ Given the growing burden of nonmelanocytic skin cancers on ageing populations and on healthcare systems, determining whether these malignancies have a viral component could have a big impact on clinical care and prevention of disease.

We therefore sought to investigate the association between seropositivity to 16 genus $\beta$ human papillomaviruses and specific subtypes of non-melanocytic skin cancers as part of an expanded analysis of our population based case-control study from New Hampshire, USA. ${ }^{12}$ As a secondary aim, we explored modifications 
of the risk associated with human papillomavirus by ultraviolet radiation and immunology related factors.

\section{METHODS}

Study population

Participants included those described in our earlier report, ${ }^{6}$ along with additional cases and controls included in a more recent enrolment phase. Briefly, to identify cases we enlisted the collaboration of dermatologists and pathology laboratories throughout New Hampshire and bordering regions. ${ }^{13}$ We selected all identified cases of histologically confirmed incident invasive squamous cell carcinoma and a random sample of histologically confirmed incident basal cell carcinoma cases (for efficiency), diagnosed between 1 July 1993 and 30 June 1995 in the initial enrolment phase and between 1 July 1997 and 31 March 2000 in the second enrolment phase. The sample of basal cell carcinoma cases was drawn concomitantly with the squamous cell carcinoma cases (at a ratio of about two basal cell carcinoma to one squamous cell carcinoma cases in the first phase and one to one in the second phase). We selected these basal cell carcinoma cases to represent the entire diagnosis group for anatomical site, age, and sex. Eligible patients included residents of New Hampshire who, at the time of diagnosis, were aged 25 to 74 years, spoke English, and had a listed telephone number. We excluded people with squamous cell or basal cell carcinomas on genital sites. We identified 2517 potential participants. Of these, we contacted and confirmed the eligibility of 2457 (98\%), of whom $2014(82 \%)$ were interviewed (1143 basal cell carcinoma and 871 squamous cell carcinoma cases).

We chose controls from among residents of New Hampshire aged 25 to 74 years who were frequency matched on age (25-34, 35-44, 45-54, 55-64, 65-69, and 70-74 years) and sex to represent the combined distribution of the squamous cell carcinoma and basal cell carcinoma cases. We selected controls (roughly equal in number to the number of basal cell carcinoma cases) from lists of New Hampshire residents provided by the New Hampshire Department of Transportation (for those less than 65 years old) and Center for Medicaid and Medicare Services (for those aged 65 and older). As with cases, we required controls to speak English and to have a listed telephone number. For interviewing purposes, we randomly assigned reference dates to controls corresponding to the cases' dates of diagnosis. Of the 1527 potential controls, 1462 (96\%) were contacted and confirmed as eligible, and 1066 $(73 \%)$ of those were interviewed.

\section{Personal interview}

All participants provided informed consent in accordance with the Committee for the Protection of Human Subjects at Dartmouth College. Study participants completed a structured personal interview, usually at their homes. To minimise reporting bias, we did not reveal the specific hypotheses of interest to either the interviewer or the participant and did not inform the interviewers of the case-control status of participants. The interview included sociodemographic information (level of education), use of tobacco, prolonged use of glucocorticoid drugs (for one month or longer) and reasons for use, assessment of pigmentary characteristics and nevi, and questions relating to skin sensitivity to the sun after first exposure in the summer (tendency to sunburn). To estimate sun exposure, we asked about the amount of time spent outdoors on work days, non-work days, and vacations, both in summer and at other times of the year; history of sunbathing; number of painful and blistering sunburns; and lifetime residential history by using a standardised instrument developed for a case-control study in Australia. ${ }^{1415}$

Beginning with cases diagnosed in 1997, we requested cases' diagnostic materials (slides and paraffin embedded tumour tissue) from the original pathology laboratory or dermatopathologist for histological verification by the study pathologist. The assessment included documentation of solar keratoses (yes/no), defined by the presence of atypical epithelial cells confined to the epidermis in adjacent skin tissue.

\section{Human papillomavirus serology}

We collected a venous blood sample of approximately $20-30 \mathrm{ml}$ in heparinised tubes. Blood was separated by centrifugation at $3000 \mathrm{rpm}$ for 20 minutes at $4^{\circ} \mathrm{C}$, and plasma, white blood cells, and red blood cells (washed twice in saline) were aliquoted and stored separately at $-80^{\circ} \mathrm{C}$ until analysis. Each specimen was labelled with a type code (plasma, red blood cells, buffy coat) and a unique identifier that did not reveal the participant's case-control status.

We analysed plasma samples for antibodies to the major capsid protein L1 of $\beta$ human papillomavirus types $5,8,9,15,17,20,23,24,36,38,49,75,76,92$, 96 , and 107 . We based our antibody detection approach on a glutathione S-transferase capture enzyme linked immunosorbent assay (ELISA) method, ${ }^{1617}$ in combination with fluorescent bead technology. ${ }^{18}$ Using this approach, full length viral proteins fused with an N-terminal glutathione S-transferase domain were expressed in Escherichia coli bacteria. Glutathione cross linked to casein was coupled to fluorescence labelled polystyrene beads (Luminex, Austin, TX), and glutathione S-transferase fusion proteins were affinity purified on the beads directly in a one step procedure. Bead types of different colour and carrying different antigens were mixed and incubated with human sera. Antibodies bound to the beads by the viral antigens were stained by biotinylated anti-human immunoglobulin and streptavidin-R-phycoerythrin. Beads were analysed in a Luminex analyser that identified the bead colourand thus the antigen carried by the bead-and antibodies bound to viral antigens were quantified by the median R-phycoerythrin fluorescence intensity of at least 100 beads of the same internal colour. Standard thresholds for a positive median R-phycoerythrin fluorescence intensity reaction were derived from a survey of 
the German general population. ${ }^{19}$ A reanalysis of our earlier data with these thresholds made no substantial difference to the results (data not shown). ${ }^{6}$

The study sera were analysed once on each of three consecutive days. As a quality control measure, a subset of 166 study sera supplemented with 21 sera with known reactivity from a previous study were tested each day. ${ }^{20}$ Pearson correlation coefficients $\left(\mathrm{R}^{2}\right)$ for the individual antigens ranged from 0.634 to 0.967 (median 0.849) for day 2 versus day 1 and from 0.544 to 0.980 (median 0.903 ) for day 3 versus day 1 . As additional quality controls, a standard serum with a known reactivity pattern to a subset of the antigens was analysed on each 96 well plate, and loading of the different beads with antigens was monitored by a monoclonal antibody against a peptide fused to the $\mathrm{C}$-terminus of all expressed antigens. ${ }^{17}$

\section{Statistical analysis}

\section{Primary analysis}

We examined the overall and sex specific prevalence of $\beta$ human papillomavirus antibody positivity according to skin cancer risk factors. We then calculated the odds ratios and 95\% confidence intervals for squamous cell carcinoma and basal cell carcinoma associated with seropositivity to $\beta$ human papillomavirus types (overall and by individual types). On the basis of earlier work, ${ }^{61019}$ we examined seropositivity to multiple types $(1,2-3,4-8$, and $>8 \beta$ types positive compared with seronegative to all $\beta$ types) and calculated a $\mathrm{P}$ value for trend based both on these categories and on a continuous variable of the number of types positive. We tested for deviation from linearity by adding polynominals (for example, a quadratic term) to the models and by examining the plot of a general additive model with loess smoothing (S-Plus 8.0, TIBCO Software). Additionally, we evaluated each genus $\beta$ species: $\beta 1$ (human papillomavirus 5, 8, 20, 24, and 36), $\beta 2$ (HPV $9,15,17,23,38$, and 107), $\beta 3$ (HPV 49, 75, and 76), $\beta 4$ (HPV 92), and $\beta 5$ (HPV 96). ${ }^{2}$ In each of these analyses, we used unconditional logistic regression, taking into account multiple confounding factors. ${ }^{21}$ Possible covariates included age, level of education (less than college, college, graduate/professional school), smoking status (never, current, former), skin sensitivity to the sun (severe sunburn with blistering, painful sunburn, mild sunburn with some tanning, and tanning with no sunburn), lifetime number of painful sunburns $(0,1-2, \geq 3)$, and oral glucocorticoid use (no, yes, and reason for use).

We classified cases according to their status as of the date of their first skin cancer diagnosed during the study period and controls as of their reference date. Classification of participants according to this plan results in relative risks estimates of incidence density ratios. $^{22}$ As a sensitivity analysis, we did analyses restricted to participants who had had no previous skin cancers to assess whether the risk estimates differed from those obtained for all participants. Additionally, we did analyses of squamous cell carcinoma excluding people who had a concomitant basal cell carcinoma ( $\mathrm{n}=58 ; 6.7 \%$ of cases). All risk estimates ultimately were adjusted for or stratified by age, sex, and sun sensitivity, and additionally for cigarette smoking for cases of squamous cell carcinoma. No other factors appreciably influenced the results. We designed our study to ensure at least $80 \%$ power with an $\alpha$ of 0.05 to detect odds ratios smaller than 2 . For example, with an $\alpha$ of $0.05,80 \%$ power, and an approximate sample size of 670 squamous cell carcinoma cases (the smaller case group) and 810 controls, our minimum detectable odds ratio calculated using conservative prevalence estimates (that is, lower than actually observed) was 1.4 for a prevalence of $20 \%$ for $\beta$ human papillomavirus seropositivity and 1.6 for a prevalence of $10 \%$ of multiple types positive.

\section{Secondary analyses}

We calculated the odds ratios for basal cell carcinoma and squamous cell carcinoma tumours separately in comparison with controls and by anatomical sites with chronic sunlight exposure (head and neck) versus other sites, as well as separately by specific site of occurrence (for example, head and neck, upper limbs, trunk, and lower limbs). We further examined subgroups of squamous cell carcinoma tumours according to the presence of adjacent actinic keratoses (yes, no). We assessed the potential modifying effects of exposure to ultraviolet light by examining odds ratios stratified by skin reaction to the sun (both in the original four categories and dichotomised) and by lifetime number of painful sunburns $(0,1-2,3-9, \geq 10)$. As human papillomaviruses have been related largely to skin cancers occurring in immunosuppressed populations, we further considered the possibility that any associations might be stronger among people with a history of prolonged use of oral glucocorticoids for reasons other than organ transplantation. In these stratified analyses, we classified participants as users if they reported using glucocorticoids for one month or longer (yes, no) and excluded those who reported having had an organ transplant.

\section{RESULTS}

Primary analysis

We obtained results on human papillomavirus serology for 2366 cases and controls (663 squamous cell carcinoma, 898 basal cell carcinoma, 805 controls) from whom a plasma sample was collected (excluding seven squamous cell carcinoma cases, two basal cell carcinoma cases, and seven controls with insufficient or unprocessed samples). We noted no appreciable case-control differences in the characteristics of people from whom we did not obtain serology data (data not shown). Looking first at the prevalence of $\beta$ human papillomavirus antibodies by participants' characteristics among controls, we found that men had a slightly higher proportion of antibody positivity to $\beta$ human papillomaviruses than did women, but the difference was not statistically significant $(48 \%$ in men $v 42 \%$ in women; $\mathrm{P}=0.11$ ) (table 1). We did not see trends in 
prevalence of antibody by age, level of education, smoking status, skin sensitivity to the sun, or number of painful sunburns (table 1).

The odds ratios for squamous cell carcinoma, but not basal cell carcinoma, were elevated for each of the $\beta$ human papillomavirus types, and each genus $\beta$ species examined; positivity to at least one $\beta$ human papillomavirus type was associated with an overall odds ratio of 0.97 (95\% confidence interval 0.80 to 1.19 ) for basal cell carcinoma and 1.30 (1.04 to 1.61$)$ for squamous cell carcinoma (table 2). We found a clear increasing trend in risk of squamous cell carcinoma with increasing number of $\beta$ human papillomavirus types positive, on the basis of both the categorical variables (odds ratio for one type positive 0.99 (0.74 to 1.33 ); odds ratio for two to three types positive 1.44 (1.03 to 2.01 ); odds ratio for four to eight types positive 1.51 (1.03 to 2.20 ); odds ratio for more than eight types positive 1.71 (1.12 to 2.62); categorical $\mathrm{P}$ for trend $<0.001$ ) and a continuous scale ( $\mathrm{P}$ for trend $=0.003$ ) (table 2$)$. The addition of a quadratic term did not improve the fit of the model, and the plot of the general additive mode did not suggest deviation from linearity (data not shown). These results did not materially change when we restricted the analysis to first skin cancers or to people with squamous cell carcinoma alone (without a concomitant basal cell carcinoma) (data not shown).

\section{Secondary analyses}

Odds ratios for squamous cell carcinoma were slightly higher among cases with histological evidence of actinic keratoses $(1.59,1.03$ to 2.44$)$ than among those

Table 1|Distribution of human papillomavirus seropositivity among control participants by age, education, smoking status, and sunlight related factors. Values are numbers (percentages)*

\begin{tabular}{|c|c|c|c|c|c|c|}
\hline \multirow[b]{2}{*}{ Variable } & \multicolumn{2}{|c|}{ Overall } & \multicolumn{2}{|c|}{ Men } & \multicolumn{2}{|c|}{ Women } \\
\hline & Total & Genus $\beta$ positive & Total & Genus $\beta$ positive & Total & Genus $\beta$ positive \\
\hline Overall & 805 & $369(46)$ & 493 & $237(48)$ & 312 & $132(42)$ \\
\hline \multicolumn{7}{|l|}{ Age (years): } \\
\hline $25-34$ & 5 & $1(20)$ & 2 & $1(50)$ & 3 & $0(0)$ \\
\hline $35-49$ & 118 & $53(45)$ & 55 & $21(38)$ & 63 & $32(51)$ \\
\hline $50-54$ & 59 & $28(47)$ & 37 & $18(49)$ & 22 & $10(45)$ \\
\hline $55-59$ & 96 & $41(43)$ & 51 & $24(47)$ & 45 & $17(38)$ \\
\hline $60-64$ & 111 & $49(44)$ & 79 & $34(43)$ & 32 & $15(47)$ \\
\hline $65-69$ & 223 & $111(50)$ & 146 & $79(54)$ & 77 & $32(42)$ \\
\hline $70-74$ & 193 & $86(45)$ & 123 & $60(49)$ & 70 & $26(37)$ \\
\hline \multicolumn{7}{|l|}{ Education: } \\
\hline High school or technical school & 376 & $170(45)$ & 224 & $108(48)$ & 152 & $62(41)$ \\
\hline College & 262 & $124(47)$ & 159 & $79(50)$ & 103 & $45(44)$ \\
\hline Graduate or professional school & 167 & $75(45)$ & 110 & $50(45)$ & 57 & $25(44)$ \\
\hline \multicolumn{7}{|l|}{ Smoking status: } \\
\hline Never & 276 & $125(45)$ & 130 & $66(51)$ & 146 & $59(40)$ \\
\hline Former & 399 & $186(47)$ & 279 & $133(48)$ & 120 & $53(44)$ \\
\hline Current & 130 & $58(45)$ & 84 & $38(45)$ & 46 & $20(43)$ \\
\hline \multicolumn{7}{|l|}{ Skin sensitivity†: } \\
\hline Severe sunburn with blistering & 43 & $19(44)$ & 21 & $10(48)$ & 22 & $9(41)$ \\
\hline Painful sunburn followed by peeling & 198 & $84(42)$ & 123 & $50(41)$ & 75 & $34(45)$ \\
\hline Mild sunburn with some tanning & 408 & $189(46)$ & 247 & $125(51)$ & 161 & $64(40)$ \\
\hline Tan without sunburn & 154 & $77(50)$ & 100 & $52(52)$ & 54 & $25(46)$ \\
\hline \multicolumn{7}{|l|}{ Lifetime No of painful sunburns: } \\
\hline None & 256 & $114(45)$ & 152 & $74(49)$ & 104 & $40(38)$ \\
\hline $1-2$ & 231 & $104(45)$ & 132 & $64(48)$ & 99 & $40(40)$ \\
\hline$\geq 3$ & 309 & $147(48)$ & 202 & $96(48)$ & 107 & $51(48)$ \\
\hline \multicolumn{7}{|l|}{ Glucocorticoid use: } \\
\hline No & 737 & $336(46)$ & 462 & $222(48)$ & 275 & $114(41)$ \\
\hline Yes & 43 & $18(42)$ & 18 & $5(28)$ & 25 & $13(52)$ \\
\hline \multicolumn{7}{|l|}{ Reason for glucocorticoid use: } \\
\hline Respiratory conditions and asthma & 10 & $3(30)$ & 3 & $0(0)$ & 7 & $3(43)$ \\
\hline Musculoskeletal and connective tissue disease & 16 & $7(44)$ & 8 & $3(38)$ & 8 & $4(50)$ \\
\hline Neoplasm/gastrointestinal disease & 6 & $3(50)$ & 2 & $0(0)$ & 4 & $3(75)$ \\
\hline Allergy & 3 & $2(67)$ & 0 & $0(0)$ & 3 & $2(67)$ \\
\hline Other/unknown & 9 & $4(44)$ & 5 & $2(40)$ & 4 & $2(50)$ \\
\hline
\end{tabular}

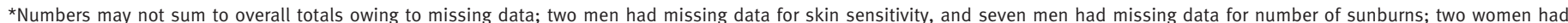
missing data for number of sunburns; these participants were excluded from further analyses.

†Defined as reaction to one hour of sun exposure first time in summer. 
Table 2 |Odds ratios for basal cell carcinoma and squamous cell carcinoma with human papillomavirus (HPV) antibody positivity

\begin{tabular}{|c|c|c|c|c|c|}
\hline \multirow[b]{2}{*}{ HPV serology results } & \multirow[b]{2}{*}{$\begin{array}{c}\text { Control-No }(\%) \\
\quad(n=805)\end{array}$} & \multicolumn{2}{|c|}{ Basal cell carcinoma $(n=898)$} & \multicolumn{2}{|c|}{ Squamous cell carcinoma $(n=663)$} \\
\hline & & No (\%) & $\begin{array}{l}\text { Adjusted odds ratio* } \\
\qquad(95 \% \mathrm{Cl})\end{array}$ & No (\%) & $\begin{array}{l}\text { Adjusted odds ratio* } \\
\qquad(95 \% \mathrm{Cl})\end{array}$ \\
\hline$\beta$ HPV seronegative & $436(54.2)$ & $502(55.9)$ & 1.00 (referent) & $311(46.9)$ & 1.00 (referent) \\
\hline$\beta$ HPV seropositive & $369(45.8)$ & $396(44.1)$ & 0.97 (0.80 to 1.19) & $352(53.1)$ & $1.30(1.04$ to 1.61$)$ \\
\hline \multicolumn{6}{|c|}{ No of $\beta$ HPV types positive: } \\
\hline 1 & $155(19.3)$ & $180(20.0)$ & 1.03 (0.79 to 1.33$)$ & $118(17.8)$ & $0.99(0.74$ to 1.33$)$ \\
\hline $2-3$ & 93 (11.6) & $98(10.9)$ & 0.97 (0.70 to 1.34$)$ & $101(15.2)$ & 1.44 (1.03 to 2.01$)$ \\
\hline $4-8$ & $71(8.8)$ & 71 (7.9) & 0.92 (0.63 to 1.33$)$ & $73(11.0)$ & 1.51 (1.03 to 2.20$)$ \\
\hline \multirow[t]{2}{*}{$>8$} & $50(6.2)$ & $47(5.2)$ & $0.90(0.58$ to 1.38$)$ & $60(9.1)$ & 1.71 (1.12 to 2.62$)$ \\
\hline & & \multicolumn{2}{|c|}{$\begin{aligned} P \text { for trend }(\text { categorical }) & =0.54 ; P \text { for trend } \\
(\text { continuous }) & =0.55\end{aligned}$} & \multicolumn{2}{|c|}{$\begin{array}{l}P \text { for trend }(\text { categorical)<0.001; } P \text { for trend } \\
\qquad(\text { continuous })=0.003\end{array}$} \\
\hline \multicolumn{6}{|l|}{ Specific $\beta$ HPV types } \\
\hline Any $\beta_{1}$ & $192(23.9)$ & $198(22.0)$ & $0.95(0.74$ to 1.22$)$ & $212(32.0)$ & $1.52(1.18$ to 1.96$)$ \\
\hline $5 \mathrm{~L} 1$ & $41(5.1)$ & $42(4.7)$ & $1.03(0.65$ to 1.64$)$ & $43(6.5)$ & $1.45(0.90$ to 2.34$)$ \\
\hline $8 \mathrm{~L} 1$ & $123(15.3)$ & $120(13.4)$ & 0.91 (0.68 to 1.23$)$ & $127(19.2)$ & 1.45 (1.08 to 1.97$)$ \\
\hline 20L1 & $122(15.2)$ & $113(12.6)$ & 0.83 (0.61 to 1.12$)$ & $131(19.8)$ & 1.45 (1.08 to 1.96$)$ \\
\hline 24L1 & $81(10.1)$ & $75(8.4)$ & $0.92(0.64$ to 1.31$)$ & $84(12.7)$ & 1.53 (1.07 to 2.18$)$ \\
\hline 36L1 & $58(7.2)$ & $55(6.1)$ & $0.89(0.59$ to 1.33$)$ & $59(8.9)$ & $1.49(0.99$ to 2.25$)$ \\
\hline Any $\beta_{2}$ & 265 (32.9) & $283(31.5)$ & 0.97 (0.77 to 1.21$)$ & $261(39.4)$ & $1.34(1.06$ to 1.7$)$ \\
\hline 9L1 & $113(14.0)$ & $114(12.7)$ & $0.96(0.70$ to 1.3$)$ & $116(17.5)$ & 1.41 (1.03 to 1.92$)$ \\
\hline 15L1 & $134(16.6)$ & $140(15.6)$ & 0.95 (0.72 to 1.27$)$ & $146(22.0)$ & 1.49 (1.11 to 1.99$)$ \\
\hline 17L1 & $132(16.4)$ & $153(17.0)$ & $1.09(0.82$ to 1.43$)$ & $134(20.2)$ & $1.37(1.02$ to 1.83$)$ \\
\hline 23L1 & $39(4.8)$ & $43(4.8)$ & 1.03 (0.65 to 1.65$)$ & $49(7.4)$ & $1.57(0.98$ to 2.52$)$ \\
\hline 38L1 & $97(12.0)$ & $94(10.5)$ & 0.91 (0.66 to 1.26$)$ & $124(18.7)$ & 1.74 (1.27 to 2.4$)$ \\
\hline 107L1 & $80(9.9)$ & $66(7.3)$ & 0.78 (0.54 to 1.13$)$ & $75(11.3)$ & $1.40(0.97$ to 2.02$)$ \\
\hline Any $\beta_{3}$ & $136(16.9)$ & $138(15.4)$ & 0.97 (0.73 to 1.29$)$ & $130(19.6)$ & 1.41 (1.05 to 1.89$)$ \\
\hline 49L1 & $115(14.3)$ & $115(12.8)$ & $0.96(0.71$ to 1.3$)$ & $114(17.2)$ & 1.47 (1.07 to 2.00$)$ \\
\hline 75L1 & $74(9.2)$ & $78(8.7)$ & $1.02(0.71$ to 1.46$)$ & $81(12.2)$ & 1.68 (1.16 to 2.43$)$ \\
\hline 76L1 & $45(5.6)$ & $44(4.9)$ & 0.95 (0.60 to 1.5$)$ & $50(7.5)$ & 1.74 (1.11 to 2.73$)$ \\
\hline$\beta_{4}(92 \mathrm{~L} 1)$ & $54(6.7)$ & $60(6.7)$ & 1.05 (0.70 to 1.58$)$ & $72(10.9)$ & 1.91 (1.28 to 2.86$)$ \\
\hline$\beta_{5}(96 \mathrm{~L} 1)$ & $67(8.3)$ & $73(8.1)$ & $1.03(0.71$ to 1.49$)$ & 88 (13.3) & 2.03 (1.40 to 2.93$)$ \\
\hline
\end{tabular}

without such evidence $(1.37,0.94$ to 2.02$)$, and we detected a stronger association between human papillomavirus and squamous cell carcinoma among those with a sun sensitive phenotype (table 3 ). We did not, however, find any notable differences according to the anatomical site of the squamous cell carcinoma tumour (data not shown) and did not find evidence of an interaction with history of sunburns. Notably, the odds ratio for squamous cell carcinoma with $\beta$ human papillomavirus positivity was about three among participants with a history of prolonged glucocorticoid use (3.21, 1.22 to 8.44 ) and closer to one among those without such a history $(1.23,0.97$ to 1.55$)$ (table 3 ). As people with a history of glucocorticoid use may also have taken other immunosuppressive drugs (such as methotrexate), we restricted the analysis to conditions primarily treated with glucocorticoids alone (for example, asthma and allergies), and the odds ratio remained higher in glucocorticoid users than in nonusers (odds ratio 1.91). However, none of the noted differences in the strata specific odds ratios achieved statistical significance.

\section{DISCUSSION}

Using a multiplex serological assay, ${ }^{18}$ we tested for a wide range of $\beta$ human papillomaviruses in plasma samples collected as part of a large population based case-control study. We detected an excess risk of squamous cell carcinoma associated with all $\beta$ human papillomaviruses examined and a clear increasing trend in risk with increasing number of $\beta$ types to which a person tested positive. We further examined factors that a priori might have been expected to modify associations. In these analyses, the association between squamous cell carcinoma and $\beta$ human papillomavirus positivity was distinctly stronger among people with a reported history of systemic glucocorticoid use.

\section{Strengths and limitations of study}

Our study included a large number of cases of histologically confirmed, invasive, incident squamous cell carcinoma that were identified through an active population based surveillance process involving dermatologists, dermatopathologists, and pathologists, as well 
Table $3 \mid$ Risk of squamous cell carcinoma stratified by $\beta$ human papillomavirus seropositivity

\begin{tabular}{|c|c|c|c|}
\hline Risk factor & $\begin{array}{c}\text { Seronegative } \\
\text { (No case/control) }\end{array}$ & $\begin{array}{c}\text { Seropositive } \\
\text { (No case/control) }\end{array}$ & $\begin{array}{l}\text { Strata specific odds ratio } \\
\qquad(95 \% \mathrm{Cl})^{\star}\end{array}$ \\
\hline \multicolumn{4}{|l|}{ Skin sensitivity†: } \\
\hline Tan without sunburn & $32 / 77$ & $36 / 77$ & $1.19(0.66$ to 2.14$)$ \\
\hline Mild sunburn with some tanning & $141 / 219$ & $154 / 189$ & $1.22(0.90$ to 1.65$)$ \\
\hline Painful sunburn with peeling & $111 / 114$ & $120 / 84$ & $1.46(0.99$ to 2.15$)$ \\
\hline Severe sunburn with blistering & $26 / 24$ & $40 / 19$ & 1.85 (0.84 to 4.07$)$ \\
\hline \multicolumn{4}{|l|}{ Skin sensitivity: } \\
\hline Tan without sunburn/mild sunburn with some tanning & $173 / 296$ & $190 / 266$ & $1.19(0.91$ to 1.56$)$ \\
\hline Painful sunburn with peeling/severe sunburn with blistering & $137 / 138$ & $160 / 103$ & 1.54 (1.09 to 2.18$)$ \\
\hline \multicolumn{4}{|l|}{ No of lifetime painful sunburns: } \\
\hline None & $82 / 142$ & $87 / 114$ & 1.31 (0.88 to 1.95$)$ \\
\hline $1-2$ & $61 / 127$ & $78 / 104$ & $1.45(0.95$ to 2.24$)$ \\
\hline $3-9$ & $43 / 62$ & $48 / 52$ & $1.32(0.75$ to 2.29$)$ \\
\hline$\geq 10$ & $121 / 100$ & $132 / 95$ & $1.17(0.80$ to 1.71$)$ \\
\hline \multicolumn{4}{|l|}{ Oral glucocorticoids: } \\
\hline No & $272 / 400$ & $295 / 336$ & $1.23(0.97$ to 1.55$)$ \\
\hline Yes & $23 / 25$ & $36 / 18$ & $3.21(1.22$ to 8.44$)$ \\
\hline \multicolumn{4}{|c|}{$\begin{array}{l}\text { * Stratum specific odds ratio for } \beta \text { human papillomavirus positivity; adjusted for age and sex for skin sensitivity and number of lifetime painful } \\
\text { sunburns; additionally adjusted for level of education, cigarette smoking status at one year before the reference date, skin sensitivity, and number of } \\
\text { lifetime painful sunburns for oral glucocorticoids. } \\
\text { †Defined as reaction to one hour of sun exposure first time in summer. }\end{array}$} \\
\hline
\end{tabular}

as controls derived from the general population. Sources used to identify controls - driver's licence and Medicare enrolment records-provide nearly complete coverage of the study population. ${ }^{23}$ Furthermore, we did not identify appreciable differences with respect to age, sex, or urban versus rural residence between people who were eligible and those who ultimately participated (data not shown). Importantly, our population based design is less susceptible to selection bias than are the clinic or hospital based studies comprising much of the skin cancer literature and is more representative of the general population than are specialised cohorts (such as organ transplant recipients). Even so, the possibility of selection bias due to nonparticipation can never be excluded; nor can we fully exclude the possibility of residual confounding. Additionally, the study is based on a US, almost exclusively white, population. Thus, generalisability to other, especially non-white, populations is uncertain.

Our study took advantage of recent technologies to measure antibodies to a wide range of cutaneous human papillomavirus types. Our finding of a trend of increase in risk of squamous cell carcinoma with increasing numbers of $\beta$ human papillomavirus types supports a possible causative role of genus $\beta$ human papillomaviruses in squamous cell carcinoma. Further proof of principle of our hypothesis was the greater magnitude of risk among people exposed to immunosuppressive drugs (systemic glucocorticoids), as expected on the basis of data from other groups of immunosuppressed patients, albeit with limited statistical precision. Importantly, we did not find an association between human papillomavirus seropositivity and immunosuppressive drug use in our control participants, suggesting that our observations were not simply a reflection of immune suppression.
By design, blood samples were collected after the diagnosis of the case. The onset of skin cancer itself might thus have resulted in increased susceptibility to infection or immune response to human papillomaviruses. If these effects existed, they must have differentially affected patients with basal cell carcinoma and squamous cell carcinoma, as we found associations only with squamous cell carcinoma. Additionally, they would have needed to be specific to $\beta$ human papillomaviruses and not other human papillomavirus types, as skin cancers have not been previously related to $\alpha$ or mucosal human papillomaviruses. ${ }^{6}$ Antibodies to human papillomaviruses generally seem to be long lived. In particular, persistence of human papillomavirus antibodies has been shown for high risk types (for example, HPV 16/18); however, limited published data exist on persistence of cutaneous human papillomaviruses. To investigate whether seropositivity was a consequence of the squamous cell tumour (and not the reverse), we analysed sera from 85 patients before and after diagnosis by using archival samples from a skin cancer prevention trial comprising patients with nonmelanocytic skin cancer followed for three to six years for the occurrence of new malignancies. ${ }^{24} \mathrm{We}$ found only one seroconversion out of the 16 who were negative for $\beta$ human papillomavirus antibodies before diagnosis (that is, one person had a positive serology result subsequent to a diagnosis of squamous cell carcinoma). On the whole, it thus seems unlikely that our observations were due simply to higher antibody titres resulting from disease onset.

The analysis reported here was limited to a comprehensive assessment of only genus $\beta$ human papillomaviruses. Other types, such as $\gamma$ human papillomaviruses, are found in non-melanoma skin cancers and are associated with risk of squamous cell carcinoma. ${ }^{11}$ Further 


\section{WHAT IS ALREADY KNOWN ON THIS TOPIC}

Genus $\beta$ human papillomaviruses are associated with occurrence of skin cancer among organ transplant recipients and people with epidermodysplasia verruciformis

Epidemiological data suggest a possible association in squamous cell carcinomas of the skin in the general population, but with study limitations

\section{WHAT THIS STUDY ADDS}

In a large population based case-control study, a wide range of genus $\beta$ human papillomavirus types were related to risk of squamous cell carcinoma but not basal cell carcinoma

A trend existed in risk of squamous cell carcinoma in relation to the number of genus $\beta$ types to which a person tested positive

The association was stronger among people who reported a history of prolonged glucocorticoid use, although statistical precision was limited

work encompassing other cutaneous human papillomaviruses is thus warranted, as are adequately powered studies to determine the risk relations for people using commonly prescribed immunosuppressive agents such as glucocorticoids.

\section{Comparison with other studies}

Although an association between seropositivity to $\beta$ human papillomaviruses and risk of squamous cell carcinoma has been observed repeatedly, ${ }^{4-11}$ data remain inconsistent as to the species or types responsible. This may be due in part to the relatively small study sizes and the narrow range of human papillomavirus types tested in previous work. A clinic based study from the Netherlands (161 squamous cell carcinoma cases and 386 controls) tested six $\beta$ human papillomaviruses (HPV 5, 8, $15,20,24$, and 38) and found elevated risks of squamous cell carcinoma for all but human papillomavirus 24 , with limited statistical precision. ${ }^{5}$ Several smaller dermatology clinic based investigations (with fewer than 100 cases of squamous cell carcinoma) found increased odds ratios for squamous cell carcinoma in relation to human papillomavirus $8 .^{4578}$ One of these also evaluated human papillomavirus 15, 36, and 23 and found an odds ratio for squamous cell carcinoma of roughly three related to human papillomavirus $36 .^{7}$ A recent clinic based study from Sweden (72 squamous cell carcinoma cases and 121 controls) found a similar prevalence of human papillomavirus antibodies in squamous cell carcinoma cases and controls but a higher prevalence among squamous cell carcinoma cases than basal cell carcinoma cases. ${ }^{25}$ However, controls comprised surgical dermatology patients in whom conditions associated with human papillomavirus infection might be overrepresented. A small nested case-control study of squamous cell carcinoma from the United Kingdom (39 squamous cell carcinoma cases and 80 controls) found no differences in prevalence of $\beta$ human papillomavirus antibodies between cases and controls but slightly higher rates among the 15 prevalent squamous cell carcinoma cases than among the 39 incident cases. ${ }^{26}$ In addition to the small study size, case ascertainment was probably incomplete owing to reliance on the regional cancer registry in this study.

As mentioned, the risk of squamous cell carcinoma in our study seemed to be more dependent on the number of $\beta$ types positive than on the specific type. Presence of multiple human papillomaviruses occurs more commonly in skin tumours of transplant recipients than in the general population (reviewed in Nindl et $\mathrm{al}^{27}$ ), and in at least one other study a higher proportion of squamous cell carcinoma cases than controls were seropositive for more than one human papillomavirus type. ${ }^{10}$ Infection with multiple types may lead to enhanced viral replication or viral capsid load, and this in turn could enhance risk of squamous cell carcinoma; however, the mechanistic basis for this observation needs to be explored further.

Skin cancers from patients with epidermodysplasia verruciformis, who have suppressed cell mediated immunity, contain $\beta$ human papillomavirus DNA. Organ transplant recipients who receive immunosuppressive drugs to prevent allograft rejection similarly have an excess of keratinocyte tumours with human papillomavirus DNA. ${ }^{28}$ Previously, we and others have reported an enhanced risk of squamous cell carcinoma associated with prolonged use of glucocorticoids for reasons other than organ transplantation and hypothesised that people taking these drugs might also be at risk of human papillomavirus related squamous cell carcinomas. ${ }^{2930}$ As mentioned, our data support this hypothesis and suggest that the known association between the human papillomavirus and occurrence of skin cancer in the presence of immunosuppression extends to drugs more commonly used by the general population.

In vitro experiments indicate that the E6 protein of several $\beta$ human papillomaviruses inhibits apoptosis induced by ultraviolet light through Bak degradation. ${ }^{31}$ Our findings provide some evidence of an interaction between exposure to ultraviolet light and human papillomavirus related risk of squamous cell carcinoma. Odds ratios were higher among people with characteristics indicative of a higher dose of ultraviolet light (sun sensitive phenotype) and to some extent with histological evidence of actinic keratoses. In contrast, we found no differences according to history of severe sunburn or stratified by tumours at chronically sun exposed sites compared with other sites. Nevertheless, ultraviolet light is a ubiquitous exposure and presents measurement challenges for epidemiological study. ${ }^{32}$ Therefore, absence of any detectable interactions would not necessarily preclude ultraviolet light's involvement in human papillomavirus induced skin cancers.

\section{Conclusions and implications}

An emerging body of evidence suggests a role of human papillomavirus in the occurrence of squamous cell carcinomas of the skin in the general population. Our findings substantiate previous observations and provide additional evidence for increasing risk with 
greater numbers of $\beta$ type infections rather than a model in which risk is associated with either a single human papillomavirus type or group of types. The plausibility of our results was reinforced by a higher magnitude of risk among users of immunosuppressive drugs, although with limited statistical power. Further mechanistic studies, along with prospective epidemiological data, could help to elucidate the natural history and timing of $\beta$ human papillomavirus infection in the pathogenesis of squamous cell carcinoma. Given the widespread and growing occurrence of these malignancies, our results raise the possibility of reducing the health and economic burden of these cancers through prevention or treatment of human papillomavirus infection.

We thank G Orth, E M de Villiers, and W Lancaster for the gift of human papillomavirus plasmids. We thank the study investigators and staff of the New Hampshire Health Study. The following physicians are members of the New Hampshire Skin Cancer Study Group: Duane R Anderson, Robert W Averill, Anthony J Aversa, Stephen Brady, Bruce A Bairstow, Richard D Baughman, Lawrence G Blasik, James Campbell, Carolyn Carroll, M Shane Chapman, William E Clendenning, Daniel W Collison, Jorge L Crespo, Frederick W Danby, Stephen M Del Guidice, Robert L Dimond, James G H Dinulos, Wilmot S Draper, Jeremy P Finkle, Judith Fisher, Jacqueline Fournier, William E Frank, John L Fromer, Norman C Goldberg, David Goldminz, Robert Gordon, David S Greenstein, Thomas P Habif, Charles Hammer, Tom Hokanson, Steve A Joselow, George Lewis, Michael D Lichter, Maritza O Liranzo, Lynette Margesson, Michael A Mittleman, Jose Peraza, Robert B Posnick, Warren M Pringle, Mark Quitadamo, Pauline B Reohr, N Chester Reynolds, Anna Ryan, Peter Sands, Mitchell E Schwartz, Gregory Seymour, Lisa D Sherman, Joan A Sisto, Steven K Spencer, James C Starke, Margaret I Stewart, Susan Sullivan, N Hakan Thyresson, Andrew P Truhan, Mauray J Tye, John Watson, K William Waterson, Robert Willer, and Kathryn Zug. Contributors: MRK, MP, HHN, and ACG were responsible for the study concept and design. MRK, TW, HHN, and MP acquired the data. All authors contributed to the analysis and interpretation of data; MRK and ZL did the statistical analyses. MRK drafted the manuscript. MRK, TW, HHN, KMM, JNBB, AEP, SKS, JD, ACG, and MP critically reviewed the manuscript for important intellectual content. MRK, MP, and HHN obtained funding. TW, HHN, KMM, JNBB, AEP, SKS, ACG, and MP provided administrative, technical, or material support. MRK, MP, and HHN supervised the study. MRK is the guarantor.

Funding: The study was funded in part by grants CA118443 and CA57494 of the US National Institutes of Health, National Cancer Institute and gran QLK2-CT-2002-01179 of the European Community. The NCl and the EC were not involved in the design and conduct of the study or the collection, management, analysis, and interpretation of the data. The contents of this manuscript are solely the responsibility of the authors and do not necessarily represent the official views of the $\mathrm{NIH}, \mathrm{NCl}$ or the $\mathrm{EC}$. Competing interests: All authors have completed the Unified Competing Interest form at www.icmje.org/coi_disclosure.pdf (available on request from the corresponding author) and declare (1) no support from any company for the submitted work; (2) no relationships with any companies that might have an interest in the submitted work in the previous 3 years; (3) their spouses, partners, or children have no financial relationships that may be relevant to the submitted work; and (4) no nonfinancial interests that may be relevant to the submitted work. Ethical approval: The Committee for the Protection of Human Subjects (CPHS) at Dartmouth College approved the study, and all participants provided informed consent in accordance with CPHS guidelines. Data sharing: No additional data available.

1 Karagas MR, Weinstock MA, Nelson HH. Keratinocyte carcinomas (basal and squamous cell carcinomas of the skin). In: Schottenfeld DFJF Jr, ed. Cancer epidemiology and prevention. 3rd ed. Oxford University Press, 2006

2 De Villiers EM, Fauquet C, Broker TR, Bernard HU, zur Hausen H. Classification of papillomaviruses. Virology 2004;324:17-27.

3 International Agency for Research on Cancer. IARC monographs on the evaluation of carcinogenic risks to humans: human papillomaviruses. Vol 90. IARC, 2007.
4 Bouwes Bavinck JN, Stark S, Petridis AK, Marugg ME, Ter Schegget J, Westendorp RG, et al. The presence of antibodies against virus-like particles of epidermodysplasia verruciformis-associated humanpapillomavirus type 8 in patients with actinic keratoses. $\mathrm{Br} J$ Dermatol 2000;142:103-9.

5 Feltkamp MC, Broer R, di Summa FM, Struijk L, van der Meijden E, Verlaan BP, et al. Seroreactivity to epidermodysplasia verruciformis related human papillomavirus types is associated with nonmelanoma skin cancer. Cancer Res 2003;63:2695-700.

6 Karagas MR, Nelson HH, Sehr P, Waterboer T, Stukel TA, Andrew A, et al. Human papillomavirus infection and incidence of squamous cell and basal cell carcinomas of the skin. J Natl Cancer Inst 2006;98:389-95.

7 Masini C, Fuchs PG, Gabrielli F, Stark S, Sera F, Ploner M, et al. Evidence for the association of human papillomavirus infection and cutaneous squamous cell carcinoma in immunocompetent individuals. Arch Dermatol 2003;139:890-4.

8 Stark S, Petridis AK, Ghim S, Jenson AB, Bouwes Bavinck JN, Gross G, et al. Prevalence of antibodies against virus-like particles of epidermodysplasia verruciformis-associated HPV8 in patients at risk of skin cancer. J Invest Dermatol 1998;111:696-701.

9 Steger G, Olszewsky M, Stockfleth E, Pfister H. Prevalence of antibodies to human papillomavirus type 8 in human sera. J Viro 1990;64:4399-406.

10 Struijk L, Hall L, van der Meijden E, Wanningen P, Bavinck JN, Neale R, et al. Markers of cutaneous human papillomavirus infection in individuals with tumor-free skin, actinic keratoses, and squamous cell carcinoma. Cancer Epidemiol Biomarkers Prev 2006;15:529-35.

11 Waterboer T, Abeni D, Sampogna F, Rother A, Masini C, Sehr P, et al. Serological association of beta and gamma human papillomaviruses with squamous cell carcinoma of the skin. Br J Dermatol 2008;159:457-9.

12 Karagas MR, McDonald JA, Greenberg ER, Stukel TA, Weiss JE, Baron JA, et al. Risk of basal cell and squamous cell skin cancers afte ionizing radiation therapy. J Natl Cancer Inst 1996;88:1848-53.

13 Karagas MR, Greenberg ER, Spencer SK, Stukel TA, Mott LA. Increase in incidence rates of basal cell and squamous cell skin cancer in New Hampshire, USA. Int J Cancer 1999;81:555-9.

14 Kricker A, Armstrong BK, English DR. Sun exposure and nonmelanocytic skin cancer. Cancer Causes Control 1994:5:367-92.

15 Kricker A, Armstrong BK, English DR, Heenan PJ. Pigmentary and cutaneous risk factors for non-melanocytic skin cancer-a casecontrol study. Int I Cancer 1991;48:650-62.

16 Sehr P, Muller M, Hopfl R, Widschwendter A, Pawlita M. HPV antibod detection by ELISA with capsid protein L1 fused to glutathione S transferase. / Virol Methods 2002;106:61-70.

17 Sehr P, Zumbach K, Pawlita M. A generic capture ELISA for recombinant proteins fused to glutathione S-transferase: validation for HPV serology. J Immunol Methods 2001;253:153-62.

18 Waterboer T, Sehr P, Michael KM, Franceschi S, Nieland J, Joos TO, et al. Multiplex human papillomavirus serology based on in situpurified glutathione s-transferase fusion proteins. Clin Chem 2005;51:1845-53.

19 Michael KM, Waterboer T, Sehr P, Rother A, Reidel U, Boeing H, et al. Seroprevalence of 34 human papillomavirus types in the German general population. PLoS Pathog 2008;4:e1000091.

20 Dondog B, Clifford GM, Vaccarella S, Waterboer T, Unurjargal D, Avirmed D, et al. Human papillomavirus infection in Ulaanbaatar, Mongolia: a population-based study. Cancer Epidemiol Biomarkers Prev 2008;17:1731-8.

21 Breslow NE, Day NE. Statistical methods in cancer research. Vol 1the analysis of case-control studies. IARC, 1980.

22 Miettinen O. Estimability and estimation in case-referent studies. Am J Epidemiol 1976;103:226-35.

23 Karagas MR, Stukel TA, Morris JS, Tosteson TD, Weiss JE, Spencer SK, et al. Skin cancer risk in relation to toenail arsenic concentrations in a US population-based case-control study. Am J Epidemiol 2001;153:559-65.

24 Greenberg ER, Baron JA, Stukel TA, Stevens MM, Mandel JS, Spencer SK, et al. A clinical trial of beta carotene to prevent basal-cell and squamous-cell cancers of the skin. $N$ Engl J Med 1990;323:789-95

25 Andersson K, Waterboer T, Kirnbauer R, Slupetzky K, Iftner T, de Villiers EM, et al. Seroreactivity to cutaneous human papillomaviruses among patients with nonmelanoma skin cancer or benign skin lesions. Cancer Epidemiol Biomarkers Prev 2008;17:189-95.

26 Casabonne D, Michael KM, Waterboer T, Pawlita M, Forslund O, Burk RD, et al. A prospective pilot study of antibodies against human papillomaviruses and cutaneous squamous cell carcinoma nested in the Oxford component of the European Prospective Investigation into Cancer and Nutrition. Int J Cancer 2007;121:1862-8.

27 Nindl I, Gottschling M, Stockfleth E. Human papillomaviruses and non-melanoma skin cancer: basic virology and clinical manifestations. Dis Markers 2007;23:247-59. 
28 Bouwes Bavinck JN, Hardie DR, Green A, Cutmore S, MacNaught A, O'Sullivan B, et al. The risk of skin cancer in renal transplant recipients in Queensland, Australia: a follow-up study. Transplantation 1996;61:715-21.

29 Karagas MR, Cushing GL Jr, Greenberg ER, Mott LA, Spencer SK, Nierenberg DW. Risk of non-melanoma skin cancer associated with glucocorticoid therapy. Br J Cancer 2001;85:683-6.

30 Sorensen HT, Mellemkjor L, Nielsen GL, Baron JA, Olsen JH, Karagas MR. Risk of skin cancers and malignant lymphomas among users of systemic glucocorticoids: a population-based cohort study. Nat Cancer Inst 2004;96:709-11.
31 Underbrink MP, Howie HL, Bedard KM, Koop Jl, Galloway DA. E6 proteins from multiple human betapapillomavirus types degrade Bak and protect keratinocytes from apoptosis after UVB irradiation. J Virol 2008;82:10408-17.

32 Karagas MR, Zens MS, Nelson HH, Mabuchi K, Perry AE, Stukel TA, et al. Measures of cumulative exposure from a standardized sun exposure history questionnaire: a comparison with histologic assessment of solar skin damage. Am J Epidemiol 2007;165:719-26.

Accepted: 25 March 2010 